\title{
Hypsometric relationship in Tectona grandis L. F. stands using quantile regression
}

\author{
Relação hipsométrica em povoamentos de Tectona grandis L. F. \\ utilizando regressão quantílica
}

Luciano Rodrigo Lanssanova ${ }^{1}$ (D), Franciele Alba da Silva ${ }^{2}$ (D), Sebastião do Amaral Machado ${ }^{2}$ (i), Allan Libanio Pelissari² (D), Afonso Figueiredo Filho ${ }^{3}$ (D) Luan Fiorentin ${ }^{2}$ (D) , Clebson Lima Cerqueira $^{2}$ (D)

${ }^{1}$ Instituto Federal de Mato Grosso - IFMT, Juína, MT, Brasil

${ }^{2}$ Universidade Federal do Paraná - UFPR, Curitiba, PR, Brasil

3Universidade do Centro-Oeste - UNICENTRO, Irati, PR, Brasil

How to cite: Lanssanova, L. R., Silva, F. A., Machado, S. A., Pelissari, A. L., Figueiredo Filho, A., Fiorentin, L., \& Cerqueira, C. L. (2021). Hypsometric relationship in Tectona grandis L. F. stands using quantile regression. Scientia Forestalis, 49(131), e3559. https://doi.org/10.18671/scifor.v49n131.07

\begin{abstract}
Quantile regression is an alternative to the traditional methods of model fitting for problems caused by the presence of outliers or asymmetry in the data distribution. Our aim was to evaluate and propose hypsometric relationship models fitting Tectona grandis L. f. stands by means of the quantile regression and least squares method. The diameter was measured at 1.3 meters from the ground and the total height of 4,068 sampled trees were divided into two bases, one for adjustment and the other for validation. Later the non-linear logistic model was adjusted via quantile regression for which the first $(0.25)$, second $(0.50)$ and third quartiles $(0.75)$ were tested. The least squares method (OLS) was also used to compare it with the quantile regression. To evaluate the precision and the adjustment of the evaluated methods, the statistics Akaike's Information Criterion (AIC), square root of the mean error (RMSE), mean absolute error (MAE) and coefficient of determination $\left(R^{2}\right)$ were used. In sequence, the analysis of variance was performed to verify the existence of significant difference between the estimate from the evaluated methods and the observed heights. The adjusted logistic model was accurate to estimate the total heights of Tectona grandis stands. Quantile regression allowed a more complete view of the relationship between response height and diameter at breast height since it was possible to build a model for each quantile of interest. Quantile regression showed good results and can be recommended for calibration of hypsometric models in Tectona grandis stands due to the ease of adjustment and implementation in forest inventories.
\end{abstract}

Keywords: Conditional quantiles; Diameter/height ratio; Simplex; Discrepant data.

\section{Resumo}

O uso da regressão quantílica é uma alternativa aos métodos tradicionais de ajuste de modelos para problemas causados pela presença de outliers ou assimetrias na distribuição de dados. Com isto, o objetivo deste trabalho foi avaliar e propor modelos de relação hippsométrica para Tectona grandis L. f. ajustados por meio do método de regressão quantílica e mínimos quadrados. O diâmetro foi medido a 1,3 metros do solo e a altura total de 4.068 árvores amostradas foi dividida em duas bases, uma para ajuste e a outra para validação. Posteriormente, o modelo logístico não linear foi ajustado através de regressão quantílica, para o qual foram testados o primeiro $(0,25)$, segundo $(0,50)$ e terceiro quartis $(0,75)$. O método dos mínimos quadrados (MMQ) também foi utilizado para compará-lo com a regressão quantilica. Para avaliar a precisão e o ajuste dos métodos avaliados, foram utilizados os critérios de informação estatística Akaike (AIC), raiz quadrada do erro médio (RMSE), erro médio absoluto (MAE) e coeficiente de determinação $\left(R^{2}\right)$. Em seqüência, a análise de variância foi realizada para verificar a existência de diferença significativa entre a estimativa dos métodos avaliados e as alturas observadas. O modelo logístico ajustado foi preciso para

Financial support: Instituto Federal de Mato Grosso, PROPES - Pró-reitoria de pesquisa.

Conflict of interest: Nothing to declare.

Corresponding author: luciano.lanssanova@jna.ifmt.edu.br

Received: 15 June 2020.

Accepted: 25 November 2020

Editor: Paulo Henrique Müller Silva. (c) This is an Open Access article distributed under the terms of the Creative Commons Attribution License, which permits unrestricted use,
distribution, and reproduction in any medium, provided the original work is properly cited. 
estimar as alturas totais dos estandes de Tectona grandis. A regressão quantílica permitiu uma visão mais completa da relação entre altura de resposta e diâmetro à altura do peito, uma vez que foi possível construir um modelo para cada quantil de interesse. Essa metodologia de ajuste mostrou bons resultados e pode ser recomendada para a calibração de modelos hipsométricos em povoamentos de Tectona grandis devido à facilidade de ajuste e implementação nos inventários florestais.

Palavras-chave: Quantis condicionais; Razão diâmetro/altura; Simplex; Dados discrepantes.

\section{INTRODUCTION}

The height estimation in a stand has a high relevance, considering the impossibility of measuring all individuals in the forest inventory, due to the time and costs related to the measurement of this variable (Floriano et al., 2006; Özçelik et al., 2018). In this sense, several researches were carried out with the purpose of minimizing costs with height measurement, such as the evaluation of simple input models for volume estimation (Lanssanova et al., 2018) and comparison of different models and methodologies to estimate the height in forest stands (Zang et al., 2016; Loureiro et al., 2016).

Models fitting to estimate height is quite usual, and the ordinary least squares estimator method is the most used in the forestry area to obtain the regression coefficients (Mendonça et al., 2011; David et al., 2016; Nicoletti et al., 2016; Cerqueira et al., 2017). This method uses the conditional means to explain the relationship between the variables of interest; however, it is influenced by extreme points and limitations for data with asymmetric and non-normally distributed (Barroso et al., 2015). In the presence of discrepant values (outliers), the use of this method may result in inadequate estimates with low accuracy and biases (Koenker \& Bassett, 1978).

The use of quantile regression is an alternative to problems caused by the presence of outliers or asymmetry in the data distribution. In addition, unlike traditional model fitting approaches, regression coefficients can be obtained through mathematical programming, such as linear programming (Koenker \& Bassett, 1978), using conditional quantiles, which makes it flexible to select the quantiles that best represents the relationship between variables (Özçelik et al., 2018).

Since the introduction of quantile regression by Koenker \& Bassett (1978), the method has been used in forestry research for self-thinning boundary lines (Zhang et al., 2005), diameter growth (Bohora \& Cao, 2014), tree taper (Cao \& Wang, 2015), and in crown modeling (Sun et al., 2017). In addition, Zang et al. (2016), adjusted height-diameter equations for Larch plantations in China. Özçelik et al. (2018) used the method in estimating tree heights from diameter for two species from Turkey: Pinus brutia Ten and Cedrus libani A. Rich. However, in Brazil there are few studies on the adjustments of diameter height equations with the quantile regression method, with the exception for the research of Pontes Neto (2012).

The aim of this work was to evaluate hypsometric relationship models fitting Tectona grandis L. f. stands by means of quantile regression. For this purpose, the hypothesis that it allows to obtain accurate estimates of the total height was considered, being an option for data with occurrence of outliers and asymmetric distribution.

\section{MATERIAL AND METHODS}

This study was carried out in seedling plantation of Tectona grandis, aged from 5 to 25 years, located in Brasnorte, Mato Grosso state, Brazil. For this purpose, the diameter outside bark at $1.3 \mathrm{~m}$ (d) and the total height (h) were measured from 4,068 sample trees. Subsequently, the descriptive statistical analysis of the data was applied, as well as the construction of a boxplot for the diameter and total height dendrometric variables in order to verify the existence of outliers.

The logistic non-linear model (1) was adjusted, in which the estimates of the regression coefficients $\left(\beta_{i}\right)$ via quantile regression were obtained through Simplex, in which the minimization of the sum of the absolute errors $\Sigma\left|y_{i}-x_{i}^{\prime} \beta\right|$ was considered as the objective function. The model was adjusted by the inner points algorithm proposed by Koenker \& Park (1996), which has the purpose 
of computing quantum regression estimates for cases in which the response function is non-linear in the parameters. For this, the quantreg package (Koenker, 2013) of the R program (R Development Core Team, 2017) was used with three quantile variations in the adjustments, evaluating the first $(0.25)$, the second (0.50) and the third quartile (0.75).

The adjustment from the least squares, on the other hand, was carried out through an iterative process with the $n / s$ function, which is indicated to adjust non-linear models (Ferreira, 2013). The program uses the Gauss-Newton algorithm as default and a maximum number of 500 iterations was specified using the maxiter function.

$h=\frac{\beta_{0}}{1+e^{\left[\frac{\left(\beta_{1}-d\right)}{\beta_{2}}\right]}}+\varepsilon$

Where: $\beta_{i}=$ regression coefficients; $\mathrm{d}=$ diameter at $1.3 \mathrm{~m}(\mathrm{~cm}) ; \mathrm{h}=$ total height $(\mathrm{m}) ; e=$ base of Napierian logarithms; $\varepsilon=$ stochastic error.

To evaluate the accuracy and adjustment of the evaluated methods, the statistics Akaike's Information Criterion (AIC) (2), square root of mean error (RMSE) (3), mean absolute error (MAE) (4) and coefficient of determination $\left(R^{2}\right)(5)$ were used. All parameters estimated by the methods tested had their significance evaluated by the $t$ test, at $\%$ significance level. Besides the adjustment and precision statistics, the residual graphs (6) as well as the estimated curves from each evaluated method were made.

$$
\begin{aligned}
& A I C=2 k-2 \ln (\hat{L}) \\
& R M S E=\sqrt{\frac{1}{n} \sum_{I}^{n}\left(y_{i}-\hat{y}_{i}\right)^{2}} \\
& \text { MAE }=\frac{1}{n}\left|y_{i}-\hat{y}_{i}\right| \\
& R^{2}=\frac{\sum_{I}^{n}\left(y_{i}-\hat{y}_{i}\right)^{2}}{\sum_{I}^{n}\left(y_{i}-\bar{y}_{i}\right)^{2}} \\
& \text { Residuals }(\%)=\frac{y_{i}-\hat{y}_{i}}{y_{i}} .100
\end{aligned}
$$

where $\hat{L}$ is the likelihood function for the model; $y_{i}$ and $\hat{y}_{i}$ are the observed and predicted values of tree height, respectively; and $\bar{y}_{i}$ is the average value of $\hat{y}_{i}$.

Of the 4,068 trees used in the research, 60 individuals were randomly separated for method validation, in which they were evaluated by the same statistics used in the adjustment. From these data, a graph was also made showing the linear correlations between the different methods evaluated and the values observed. Afterwards, analysis of variance was performed to verify the existence of significant difference between the estimate from the evaluated methods and the observed heights. Then, the multiple comparison procedure was applied through Tukey's test to the 95\% probability level.

\section{RESULTS AND DISCUSSION}

Table 1 shows the minimum, mean, maximum, quantiles values of the distribution and the respective coefficients of variation of total height $(\mathrm{h})$ and diameter at $1.3 \mathrm{~m}(\mathrm{~d})$. Although 
the variable diameter has a high range between maximum and minimum of $48.38 \mathrm{~cm}$, it has a low interquartile range of $5.29 \mathrm{~cm}$, as well as symmetrical distribution. From the $3 \mathrm{rd}$ quartile of total height it is possible to infer that $75 \%$ of the individuals measured are below $19.8 \mathrm{~m}$, the maximum value of the set is $28.8 \mathrm{~m}$.

Table 1. Descriptive statistics of the variables diameter at $1.3 \mathrm{~m}(\mathrm{~d})$ and total height $(\mathrm{h})$ for Tectona grandis

\begin{tabular}{cccccccc}
\hline \multirow{2}{*}{ Variable } & \multicolumn{7}{c}{ Descriptive statistics } \\
\cline { 2 - 8 } & $\boldsymbol{x}_{\min }$ & $\overline{\boldsymbol{x}}$ & Q1 & Q2 & Q3 & $\boldsymbol{x}_{\text {max }}$ & \multicolumn{1}{c}{ cv\% } \\
\hline Diameter at 1.3 $\mathrm{m}(\mathrm{cm})$ & 4.45 & 18.67 & 15.59 & 18.14 & 20.88 & 52.83 & $19.92 \%$ \\
Total height $(\mathrm{m})$ & 4.4 & 17.09 & 14.3 & 16.9 & 19.8 & 28.8 & $21.76 \%$ \\
\hline
\end{tabular}

$x_{\text {min }}=$ minimum value; $\bar{x}=$ arithmetic mean; $\mathrm{Q} 1=$ first quartile; $\mathrm{Q} 2$ = second quartile; $\mathrm{Q} 3=$ third quartile; $x_{\max }=$ maximum value; e $c v \%$ = coefficient of variation.

Discrepant values were observed in the data set (Figure 1), for both diameter and total height, the curve that shows the relationship between these two variables was quite steep, possibly due to factors related to age and site quality (Machado et al., 2008). Considering a stand of the same age, the individuals that develop in sites of better quality will have bigger diameter and height in relation to the trees in bad sites. Thus, the slope of the hypsometric curve tends to reduce in the most productive sites to the less productive ones (David et al., 2016).

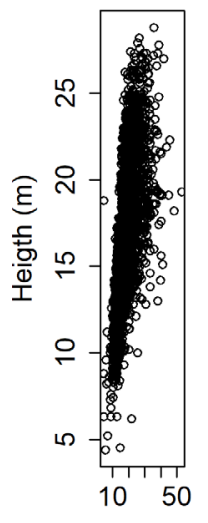

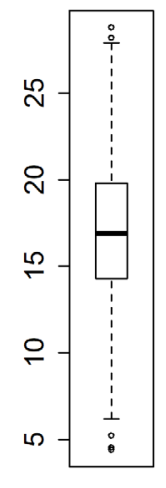

Heigth

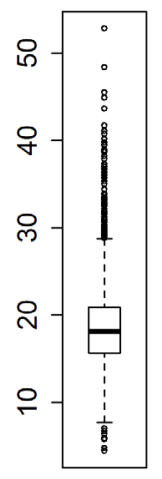

Diameter

Figure 1. Scatter plot and boxplot of the variables diameter at $1.3 \mathrm{~m}$ and total height for Tectona grandis.

The adjustment and precision statistics showed similar results for the different quantile positions in the adjustment as well as for the least squares method (Table 2). It is worth noting that although the coefficient of determination is not an adequate measure to evaluate the adjustment of non-linear models (Juliano \& Williams, 1987; Spiess \& Neumeyer, 2010), it is a commonly used measure and easy to interpret when evaluating models with forest variables (Schröder et al., 2014). All coefficients by the four methods evaluated were significant at $p<0.01$ by t-test.

Table 2. Regression coefficients and goodness of fit of the hypsometric relationship models in different quantiles for Tectona grandis.

\begin{tabular}{|c|c|c|c|c|c|c|c|c|c|c|}
\hline \multirow{2}{*}{ Method } & \multicolumn{3}{|c|}{ Coefficients } & \multicolumn{4}{|c|}{ Fit } & \multicolumn{3}{|c|}{ Validation } \\
\hline & $\mathbf{B}_{0}$ & $B_{1}$ & $\mathbf{B}_{2}$ & $\mathbf{R}^{2}$ & AIC & RMSE & MAE & $\mathbf{R}^{2}$ & RMSE & MAE \\
\hline MQO & $21.49 * *$ & $11.169 * *$ & $4.692 * *$ & 0.51 & 19104.06 & 2.57 & 2.03 & 0.80 & 2.62 & 2.02 \\
\hline Quantile (0.25) & $18.84 * *$ & $10.77 * \star$ & $4.47 * \star$ & 0.51 & 19613.11 & 3.12 & 2.43 & 0.79 & 3.36 & 2.38 \\
\hline Quantile (0.50) & $21.94 * *$ & $11.30 * *$ & $5.15 * *$ & 0.51 & 19390.69 & 2.57 & 2.02 & 0.81 & 2.56 & 1.98 \\
\hline Quantile (0.75) & $24.77^{* *}$ & $11.68 * \star$ & $5.20 * *$ & 0.51 & 19979.68 & 3.16 & 2.51 & 0.81 & 2.95 & 2.52 \\
\hline
\end{tabular}

B'is = Regression coefficients; AIC = Akaike information criterion (AIC); RMSE = root mean squared error (RMSE), $\mathrm{R}^{2}=$ coefficient of determination (R2) and MAE = mean absolute error (MAE). 
The quantile regression, using Q2 (0.50), which coincides with the mean of the data distribution, resulted in higher fitting statistics than the other quantiles evaluated. Possibly, this is because the mean and the median are the most appropriate position measurements to represent normally distributed datasets.

The quantile regression gives a more complete view of the relationship between the studied variables, since it allows to observe the functional relationship in different levels of the response variable, since they are able to incorporate a possible heteroscedasticity, which would be detected from the variation of the parameter estimates in the different quantiles evaluated (Santos, 2016). In this way, it is possible to outline the relation in central regions of the distribution, through the median and in the tails of the conditional distribution, as done in this work, using quantiles 0.25 and 0.75 .

Thus, it is possible to evaluate the behavior of the asymptote (parameter $\beta_{0}$ ) and the inflection point (parameter $\beta_{l}$ ) in the Logistic model for the three quantiles tested (Table 2). The inflection point, which represents the value of the independent variable (diameter) where the dependent variable (height) reaches the half of $\beta_{0}$ (Mendonça et al., 2011), was similar for the three quantiles evaluated. This is because the central tendency measures (average and median) are close (Table 1), since the data distribution does not present a strong asymmetry, with an asymmetry coefficient equal to 0.15 . For the upper horizontal asymptote, which corresponds to the maximum value of the variable (height) in the different quantiles tested, it was verified that the maximum height was $24.84 \mathrm{~m}$ for Q3, and $18.88 \mathrm{~m}$ for Q1.

We present the graphical residual analysis for the different methods evaluated for height estimation in Figure 2. The result obtained by the evaluated methods was not robust to the presence of outliers, indicating that the presence of discrepant data is not influencing the estimation of the curve adjusted by quantum regression (Barroso et al., 2015). In general, the residual dispersion (Figure 2) for the heights estimated by the different methods evaluated showed homogeneity of variance in all estimated height classes, with few points presenting a variation above 100\% amplitude. In addition, the residuals showed no bias, with proportionality between estimates for the response variable. The main difference between the estimates of the quantile regression and the ordinary least squares method is the distance of the points observed by the estimated curve, which is measured by minimizing the weighted average of the sum of the vertical distances in the quantile regression. Thus, for points below the line, weight equal to 1 subtracted from the established quantile is attributed, as in the present research, used for $0.25,0.50$ and 0.75 , whereas for points above the line, the weight is related to the quantile value (Hao \& Naiman, 2007).

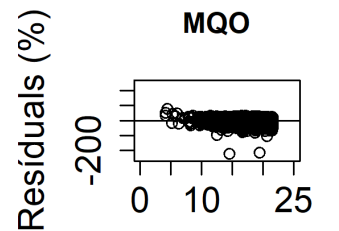

Estimated Heigth

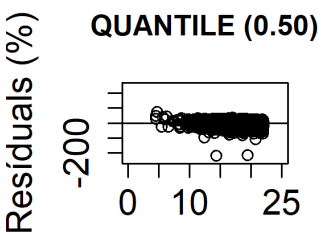

Estimated Heigth
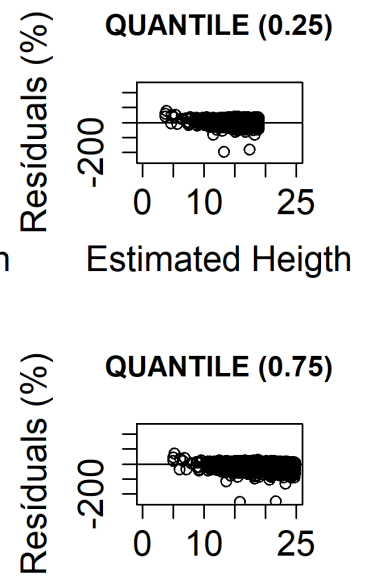

Estimated Heigth

Figure 2. Residual plots and observed versus adjusted values for the different methods evaluated for the height estimate. 
Figure 3 shows the curves adjusted by the method of least squares and quantile regression considering the three quantiles evaluated $(0.25,0.50,0.75)$. Thus, it was possible to evaluate the impact of the diameter at breast height on the entire distribution of total height, and not only on its mean. Different diameter results in quantiles are related to differences in height response to changes in coefficients at various points in the conditional distribution of the variable depends (Silva \& Porto Júnior, 2006).

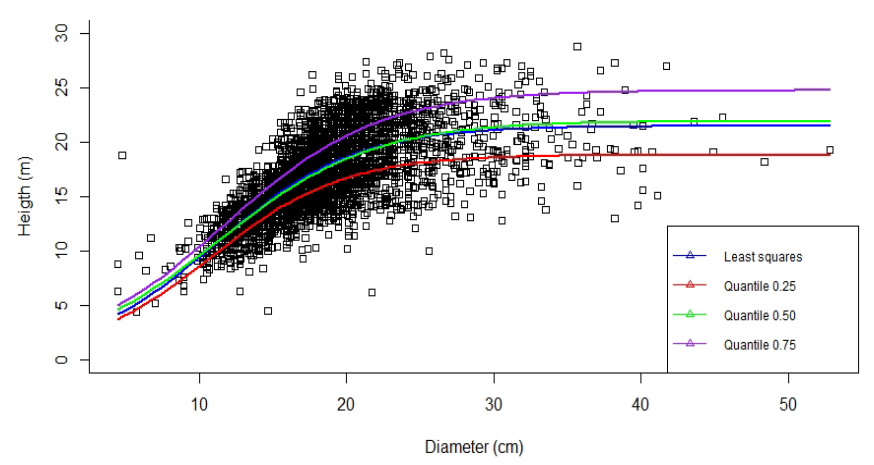

Figure 3. Curves estimated for total height by the different evaluated methods.

The ages that compose the sample for the adjustment of the model varied from 5 to 16 years (Figure 4). The first quantile evaluated (0.25) yielded the lowest error (4.45\%) for the estimation of heights with ages below 8 years. The third quantile $(0.75)$ and the least squares method presented the largest errors for this same age range, with $14.99 \%$ and $5.26 \%$, respectively.

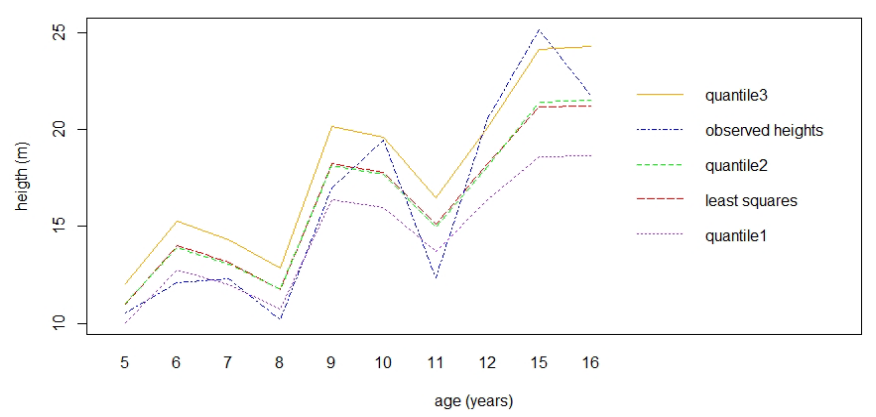

Figure 4. Interaction between different methods for estimating total height and age for Tectona grandis.

The general non-linear regression model, based on the mean regression technique, was not able to fully describe the height-diameter relationship (Figure 4). Thus, it is possible to observe the flexibility of the quantum regression when describing different patterns of heightdiameter relation (Fu et al., 2018; Özçelik et al., 2018; Zhang et al., 2020).

The results of quantile regression using the median were similar to regression based on modeling the mean of the data. Thus, the model adjusted with the quantile at 0.50 covered most of the observations predicted by the method of least squares. Cade \& Noon (2003) and Muggeo et al. (2013) found similar results.

Heights above 22 meters were not estimated by the traditional method of regression. By using quantum regession with the quantile third (0.75), it was possible to predict the variable of interest in this range of distribution (Figure 4). Thus, it is verified that the quantile regression estimates several ranges of changes, from minimum to maximum, providing a more complete picture of response when compared to the method of least squares.

In this context, quantile regression estimates can be used to construct forecast and tolerance intervals without assuming any parametric error distribution and without specifying how heterogeneity of variance is linked to changes in means (Puiatti et al., 2018). In a fully 
parametric model where the error distribution takes some specified form, the various quantiles of the response distribution are estimated by a specified multiple of the estimated standard deviation of the parametric error distribution, which is then added to the estimated mean function (Cade \& Noon, 2003).

In the data used for validation, all the methods evaluated performed well, with $\mathrm{R}^{2}$ ranging from 0.79 to 0.81 , and with low RMSE and MAE ranging from 2.56 to 3.36 and 1.98 to 2.52, respectively. All linear correlations between the different methods and the heights observed in the field were all greater than 0.89 (Figure 5).

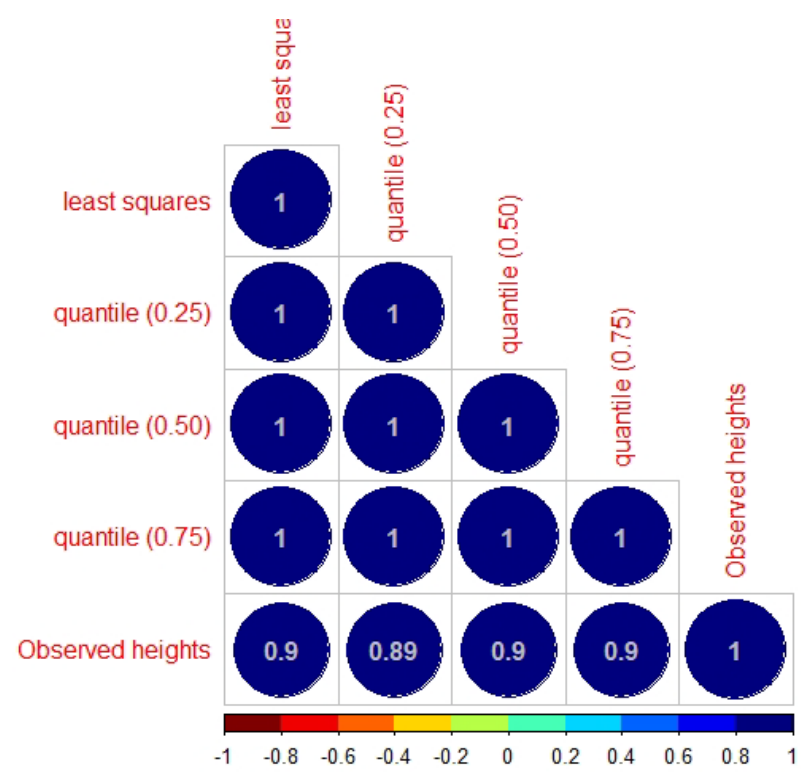

Figure 5. Pearson's linear correlation between the different evaluated methods and the observed heights

The comparative analysis of variance between the different methods showed that there was a significant difference between the methods, at the level of 5\% significance (Tables 3 and 4). Thus, when proceeding with the test of means, it was verified that the methods evaluated are more distant from the observed values, referring to the amounts 0.25 and 0.75 , respectively. The other evaluated methods do not differ statistically from the observed heights.

Table 3. Analysis of variance for the different methods to estimate the total height.

\begin{tabular}{cccccc}
\hline FV & GL & SQ & QM & $\boldsymbol{F}_{\text {calculate }}$ & $\boldsymbol{P}_{\text {value }}$ \\
\hline Métodos & 4 & 347.2 & 86.79 & $4.88^{*}$ & 0.0007 \\
Resíduos & 295 & 5243.4 & 17.77 & & \\
\hline
\end{tabular}

Table 4. Averages test for the different methods evaluated to estimate the height of Tectona grandis.

\begin{tabular}{cc}
\hline Methods & Averages \\
\hline Quantile 3 (0.75) & $17.92 \mathrm{a}$ \\
least squares & $16.16 \mathrm{ab}$ \\
Quantile 2 (0.50) & $16.16 \mathrm{ab}$ \\
Observed values & $16.14 \mathrm{ab}$ \\
Quantile 1 (0.25) & $14.52 \mathrm{~b}$ \\
\hline
\end{tabular}

The quantile regression is based on the minimization of the absolute errors, allowing to evaluate the impact of the independent variables in different positions along the distribution of the dependent variable (Koenker \& Bassett, 1978), unlike the traditional regression through 
the mean as a measure of position. Thus, it is possible to evaluate the response of each quantile, as in the present research, using the quantiles $0.25,0.50$ and 0.75 . It is important to emphasize that the choice of the quantile can also be considered as a solution to a given absolute minimization problem (Hao \& Naiman, 2007).

The quantile regression is based on the minimization of the absolute errors, allowing to evaluate the impact of the independent variables in different positions along the distribution of the dependent variable (Koenker \& Bassett, 1978), unlike the traditional regression through the mean as a measure of position. Thus, it is possible to evaluate the response of each quantile, as done in this research, using the quantiles $0.25,0.50$ and 0.75 . It is important to emphasize that the choice of the quantile can also be considered as a solution to a given absolute errors minimization problem (Hao \& Naiman, 2007).

The fitting of hypsometric models in researches in Brazil is almost predominantly performed by the method of ordinary least squares (Caldeira et al., 2003; Bartoszeck et al., 2004; Machado et al., 2008; Oliveira et al., 2015; Nicoletti et al., 2016; Cerqueira et al., 2017; Souza et al., 2017; Schmitt, 2017). However, quantile regression may be an alternative, due to the ease of fit and implementation in forest inventories. In addition, it can be applied to asymmetric data sets, whose presence of outliers can influence the fit of the model, resulting in a more robust method than traditional fittings (Barroso et al., 2015).

\section{CONCLUSIONS}

The adjusted logistical model was accurate to estimate the total heights of Tectona grandis stands. The median quantile regression was efficient to adjust the non-linear regression model from the measured diameters, being an alternative for the adjustment of hypsometric models, due to the ease of adjustment and implementation in forest inventories.

The quantile regression allows a complete view of the relationship between the response variable and the observed covariates, since it is possible to build a model for each quantile of interest. Thus, it becomes an option that makes it possible to adjust several hypsometric curves referring to different quantiles of the distribution.

\section{REFERENCES}

Barroso, L. M. A., Nascimento, M., Nascimento, A. C. C., Fonseca e Silva, F., Cruz, C. D., Bhering, L. L., \& Ferreira, R. P. (2015). Methodology for adaptability and stability analysis through quantile regression. Pesquisa Agropecuária Brasileira, 50(4), 290-297.

Bartoszeck, A. C. P. S., Machado, S. A., Figueiredo Filho, A., \& Oliveira, E. B. (2004). Dynamics of the hypsometric relationship as a function of age, site and initial density of bracatinga stands in the Metropolitan Region of Curitiba. Revista Árvore, 28(4), 517-533.

Bohora, S. B., \& Cao, Q. V. (2014). Prediction of tree diameter growth using quantile regression and mixed-effects models. Forest Ecology and Management, 319, 62-66.

Cade, B. S., \& Noon, B. R. (2003). A gentle introduction to quantile regression for ecologists. Frontiers in Ecology and the Environment, 1(8), 412-420.

Caldeira, M. V. W., Schumacher, M. V., Scheeren, L. W., \& Watzlawick, L. F. (2003). Hypsometric relation for Araucaria angustifolia (Bert.) O. Ktze in west Parana. Revista Acadêmica: Ciência Animal, 1(2), 7988. http://dx.doi.org/10.7213/cienciaanimal.v1i2.14925.

Cao, Q. V., \& Wang, J. (2015). Evaluation of methods for calibrating a tree taper equation. Forest Science, 61(2), 213-219.

Cerqueira, C. L., Môra, R., Lenzi, I. L. C., Drescher, R., Lima, E. M., Lisboa, G. S., \& França, L. C. J. (2017). Modeling height of Pinus caribaea var. hondurensis in different spacing. BIOFIX Scientific Journal, 2(2), 93-99.

David, H. C., Arce, J. E., Péllico Netto, S., Dalla Corte, A. P., Marinhesky Filho, A., \& Araújo, E. G. (2016). Thinning and site quality effects on the height-diameter relationship of Pinus taeda. Floresta $e$ Ambiente, 23(2), 220-228.

Ferreira, D. F. (2013). Computing resources using R. Lavras: Federal University of Lavras. 
Floriano, E. P., Muller, I., Finger, C. A. G., \& Schneider, P. R. (2006). Fitting and selecting traditional models for tree's height time series data. Ciência Florestal, 16(2), 177-199.

Fu, L., Lei, X., Sharma, R. P., Li, H., Zhu, G., Hong, L., You, L., Duan, G., Guo, H., \& Lei, Y. (2018). Comparing height-age and height-diameter modelling approaches for estimating site productivity of natural uneven-aged forests. For. International Journal of Forestry Research, 91, 419-433.

Hao, L., \& Naiman, D. Q. (2007). Quantile regression (126 p.). Beverly Hills: Sage Publications.

Juliano, S. A., \& Williams, F. M. (1987). A comparison of methods for estimating the functional response parameters of the random predator equation. Journal of Animal Ecology, 56(2), 641-653.

Koenker, R. (2013). quantreg: quantile regression. R Package Version 4.91. Retrieved in 2020, June 15, from https://cran.r-project.org/web/packages/quantreg/index.html

Koenker, R., \& Park, B. J. (1996). An interior point algorithm for nonlinear quantile regression. Journal of Econometrics, 71(1-2), 265-283.

Koenker, R., \& Bassett, G. (1978). Regression quantiles. Econometrica, 46(1), 33-50.

Lanssanova, L. R., Alba da Silva, F., Schons, C. T., \& Pereira, A. C. (2018). Comparison between different methods for volumetric estimation of Amazonian commercial species. BIOFIX Scientific Journal, 3(1), 109-115

Loureiro, G. H., Sanquetta, C. R., Castro, R. V. O., \& Arce, J. E. (2016). Hypsometric relationship by using regression models and artificial neural networks for Pinus taeda. Enciclopédia Biosfera, 13(24), 247262. http://dx.doi.org/10.18677/EnciBio_2016B_046.

Machado, S. A., Nascimento, R. G., Augustynczik, A. L. D., Silva, L. C. R., Figura, M. A., Pereira, E. M., \& Téo, S. J. (2008). Behavior of the hypsometric relationship of Araucaria angustifolia in the forest copse of the faculty of forest - Federal University of Paraná, Brazil. Pesquisa Florestal Brasileira, 56, 5-16.

Mendonça, A. R., Calegario, N., Silva, G. F., Borges, L. A. C., \& Carvalho, S. P. C. (2011). Height diameter relationship and growth in height the dominant and codominant trees model to Pinus caribaea var. hondurensis. Scientia Forestalis, 39(90), 151-160.

Muggeo, V. M. R., Sciandra, M., Tomasello, A., \& Calvo, S. (2013). Estimating growth charts via nonparametric quantile regression: a practical framework with application in ecology. Environmental and Ecological Statistics, 20(4), 519-531.

Nicoletti, M. F., Souza, K., Silvestre, R., França, M. C., \& Rolim, F. A. (2016). Hipsometric rate for Pinus taeda L. at different stages of the cutting cycle. Floresta e Ambiente, 23(1), 80-89.

Oliveira, G. M. V., Mello, J. M., Altoé, T. F., Scalon, J. D., Scolforo, J. R. S., \& Pires, J. V. (2015). Hypsometric equations for unmanaged Eucalyptus spp. in old age with techniques for the inclusion of covariates. Cerne, 21(3), 483-492.

Özçelik, R., Cao, Q. V., Trincado, G., \& Göçer, N. (2018). Predicting tree height from tree diameter and dominant height using mixed-effects and quantile regression models for two species in Turkey. Forest Ecology and Management, 419-420, 240-248.

Pontes Neto, T. P. (2012). Comparison of linear and nonlinear models in hypsometric relationships for clones of Eucalyptus spp., at the region of Gypsum Pole of Araripe (PhD thesis). Universidade Federal Rural de Pernambuco, Recife.

Puiatti, G. A., Cecon, P. R., Nascimento, M., Nascimento, A. C. C., Carneiro, A. P. S., Silva, F. F., Puiatti, M., \& Oliveira, A. C. R. (2018). Quantile regression of nonlinear models to describe different levels of dry matter accumulation in garlic plants. Ciência Rural, 48(1), 1-6.

R Development Core Team. (2017). R: a language and environment for statistical computing. Vienna: R Foundation for Statistical Computing. Retrieved in 2020, June 15, from http://www.R-project.org/

Santos, P. M. (2016). Quantile regression applied to the study of genomic selection for asymmetric characteristics of pigs (Master thesis). Universidade Federal de Viçosa, Viçosa.

Schmitt, T. (2017). Hypsometric relationship of clonal Eucalyptus in southern Tocantins (Master thesis). Universidade Federal do Tocantins, Gurupi.

Schröder, T., Arnoni, E. C., Valério, A. F., \& Lisboa, G. S. (2014). Taper equations for Pinus elliottii Engelm. in Southern Paraná, Brazil. Forest Science, 61(2), 311-319.

Silva, E. N., \& Porto Júnior, S. S. (2006). Financial system and economic growth: an application of quantile regression. Economia Aplicada, 10(3), 425-442.

Souza, A. S., Santos, J. X., \& Souza, D. V. (2017). Modeling height-diameter relationship for a hybrid eucalyptus stand in the brazilian amazon. BIOFIX Scientific Journal, 2(1), 44-53. http://dx.doi.org/10.5380/biofix.v2i1.51395. 
Spiess, A. N., \& Neumeyer, N. (2010). An evaluation of $\mathrm{R}^{2}$ as an inadequate measure for nonlinear models in pharmacological and biochemical research: a Monte Carlo approach. BMC Pharmacology, 10(6), 6 .

Sun, Y., Gao, H., \& Li, F. (2017). Using linear mixed-effects models with quantile regression to simulate the crown profile of planted Pinus sylvestris var. Mongolica trees. Forests, 8(11), 446.

Zang, H., Lei, X., \& Zeng, W. (2016). Height-diameter equations for larch plantations in northern and northeastern China: a comparison of the mixed-effects, quantile regression and generalized additive models. Forestry, 89(4), 434-445.

Zhang, B., Sajjad, S., Chen, K., Zhou, L., Zhang, Y., Yong, K. K., \& Sun, Y. (2020). Predicting tree heightdiameter relationship from relative competition levels using quantile regression models for chinese fir (Cunninghamia lanceolata) in Fujian Province, China. Forests, 11(183), 2-15.

Zhang, L., Bi, H., Gove, J. H., \& Heath, L. S. (2005). A comparison of alternative methods for estimating the self-thinning boundary line. Canadian Journal of Forest Research, 35(6), 1507-1514.

Authors' contributions: LRL: Conceptualization, data curation, formal analysis, funding acquisition, methodology, writing original draft preparation, writing; FAS: writing-review and editing; SAM: writing-review and editing; ALP: writing-review and editing; AFF: writing-review; LF: writing review; CLC: writing-review. 